\title{
Disseminated Peritoneal Leiomyomatosis
}

National Cancer Institute

\section{Source}

National Cancer Institute. Disseminated Peritoneal Leiomyomatosis. NCI Thesaurus. Code C3958.

A rare, benign process that affects the peritoneal cavity and is characterized by the formation of multiple small nodules that are composed of well differentiated smooth muscle. It usually affects adults in their late reproductive years. Most patients are asymptomatic. The tumor nodules may regress spontaneously. 